\title{
Energy Efficiency of a Vernacular Building Design and Materials in Hot Arid Climate: Experimental and Numerical Approach
}

\author{
Karima El Azhary*, Mohamed Ouakarrouch, Najma Laaroussi, Mohammed Garoum \\ Mohammed V University in Rabat, EST Salé, Materials, Energy and Acoustics Team (MEAT), Avenue Prince Héritier, B.P : 227 Salé, \\ Morocco
}

\begin{abstract}
Morocco faces tremendous climate constraints; the climate is hot and dry in most parts of the country, and when selecting an energy-saving approach, the architectural landscape becomes essential. Designer and building professionals seem to have neglected this large-scale integration. Sustainable development programs in terms of sustainable architecture are ongoing in countries around the world. One part of this trend is the growing concern shown in the high environmental efficiency of vernacular architecture. It is within this prescriptive framework that this research study is being conducted, which reveals novel architectural style integrating thermal comfort, energy efficient characteristics, passive solar elements architecture, and construction techniques inspired from the vernacular Ksourian architectural configurations. The goal of the present research study is to identify features of energy efficient vernacular architecture and thermal performances that affect indoor thermal comfort conditions for adaptation to current lifestyles in modern architecture. The key characteristics developed are; built mass structure, building orientation, space planning, availability of sunspace, building techniques, and new coating materials for manufacturing and roofing. The suggested methodology enables to analyze the thermal performance analysis, applying an experimental research using experimental testing measurement and comparative optimization processes for thermal efficiency and comfort evaluation of a traditional vernacular earthen house. Series of experimental thermophysical characterization measurements have been carried out in order to quantify on a real scale the thermophysical properties that characterize the Rissani earth. Thus thermophysical characterization results are operated as input data for the thermal dynamic simulation for the purpose to evaluate thermal performances and comfort under the weather conditions and control natural comfort in both summer and winter, without using heating or cooling systems. Ultimately, the simulations carried out make it possible to identify the optimal orientation, revealing an effective decrease in interior temperatures during summer and providing good thermal comfort in winter.
\end{abstract}

Keywords: Earthen building, thermophysical characterization, energy efficiency, thermal dynamic simulation, thermal comfort.

Article History: Received: 20th Dec 2020; Revised: 25th January 2021; Accepted: 10 ${ }^{\text {th }}$ February 2021; Available online: 18th Feb 2021

How to Cite This Article: El-Azhary, K., Ouakarrouch, M., Laaroussi, N., Garoum, M (2021). Energy Efficiency of a Vernacular Building Design and Materials in Hot Arid Climate: Experimental and Numerical Approach. Int. Journal of Renewable Energy Development, 10(3), 481-494. https://doi.org/10.14710/ijred.2021.35310

\section{Introduction}

The alleged looming shortage of fossil fuels is now highlighting the need to concentrate on the use of sustainable and green energies and its technological, environmental and socio-economic impacts in the area of residential building. The building sector (residential and tertiary) today accounts for slightly more than a third of the world's final energy consumption, in developing countries as a whole, the share of its consumption exceeds 40\% (Liébard et al. 2007). Residential sector consumption in Morocco amounted to almost 6.5 Mtep, representing $33 \%$ of the national energy consumption (RTCM, 2012). Morocco is experiencing an intense housing crisis in terms of thermal comfort and thermal behavior that designers and architects have often excluded and ignored (Terrasse, 1998). Recently, and steadily, policymakers and professionals in the construction industry in Morocco are recognizing the pressing need for a more sustainable approach to building architecture and construction. It is assumed that the only way for the nation to minimize the growing rate of emissions and reduce electricity is by enforcing strict environmental and sustainability standards in construction practice.

As a result, vernacular buildings such as ksours and traditional media-style houses have faced some climatic and environmental challenges by adapting perfectly to different climates (humid, semi-arid, arid and desert) (ENA, 2016). The ksar is a typology of fortified Saharan and semi-Saharan towns and/or villages, it is an environmental ecosystem that facilitates occupation. The ksar tends to be an adequately compact component, dominated by clay color, closely linked to the green space of the oasis. Originally, it is a collective granary which serves as a place for ensilage of cereals, olives, livestock products; it is also a safe place where valuables are secure (Mecca, 2006). They represent sustainable buildings, using traditional temperature-regulating materials such as mud, clay, stone and wood, thick walls and wide roofs to produce the required inertia and good indoor thermal

\footnotetext{
* Corresponding author: elazhary.karima@gmail.com
} 
comfort. The impact of urban changes on cultural heritage is not taken into account, although this concern represents a wealth of resources for sustainable building practices (Ravéreau, 2007). The vernacular architecture may be a resource for contemporary architecture according to (Creangă et al. 2010). The product of a delicate equilibrium between material, shape, and the natural environment, vernacular architecture could become an incredibly useful model of inspiration for the present. Various aspects have an effect on earth building thermal comfort besides its energy efficiency, including thermophysical properties of construction materials, insulation, building orientation, volume distribution when bringing together several innovative and conventional passive energy saving solutions (Fernandes et al. 2018). The choice of building orientation, as stated by Givoni, (1978), is subject to several relevant factors; furthermore, the facade orientation, the wind and sun building exposition affect the interior atmosphere. In the face of this problem, occupancy will resort to physical equipment, resulting in extreme consumption of electricity. Passive strategies that are responsive to temperature changes can stimulate unregulated indoor conditions, while technologies that allow the influence of the natural atmosphere can be adapted at any time (Alexandroff, 1982). Passive techniques are primarily based on integrating the building into its environment, and then on the architecture that incorporates the latest technology related to the development, storage and delivery of energy to supply much more sun heating (Sayigh, 2013).

There have been a number of research studies on traditional buildings, but especially on human or social sciences. In addition, few of them have sustainability, thermal engineering and environmental behaviour. In terms of thermal comfort, it is commonly accepted that the engineering methods used in vernacular architectural projects create a comfortable interior atmosphere when the thermal gap with the outside exceeds approximately $10^{\circ}$ (Hyde, 2008). Baross et al. (2017) presented an overview of the receptive envelopes and shading systems used in vernacular architecture, providing a summary of the different modeling techniques and a short description of the case studies. Soflaei et al. (2017) investigated the factors of the social and economic growth of contemporary courtyard buildings in Iran and China. Dayaratne et al. (2010) have shown that in vernacular designs, courtyard orientation is a principal key to improving energy efficiency and enhancing indoor thermal comfort conditions in the arid areas of Sri Lanka. Moreover El Azhary et al. (2019) studied Study investigated the effect of traditional architecture on the thermal efficiency of dwellings in Southern Morocco, while proving the role of the exterior enclosure in supplying the requisite thermal comfort. Fernandez et al. (2018) treated the effects of climate-responsive strategies on thermal performance and indoor comfort of earthen architecture from Northern Egypt and Southern Portugal.

The earthen materials constitute a key element of Ksourian vernacular constructions, for this reason, identifying the thermal properties of earth material is necessary. El Azhary et al. (2017) studied the different scenarios for improving energy efficiency of vernacular housing using thermophysical characterization of unfired clay bricks used for building construction in the south Morocco. Ouakarrouch et al. (2020) investigated in their research study the thermal properties of unfired clay bricks reinforced by sisal fibers used in construction of Maadid Ksar courtyards located in the southern region of Morocco. There are very few studies carried out to classify the energy quality and thermal output of Moroccan vernacular architecture in quantity and variety and they have concentrated closely on the patio layout of the Riads that dominate the country's typical architectural landscape.

These studies have as main objective to improve the resistance and durability of the earth as a building material and studies of thermal comfort of vernacular houses are identified as complementary research areas, these aspects have been treated separately. On the other hand, the studies carried out to treat the vernacular architecture of the Ksours of Morocco are limited to the treatment of the social aspect, architectural heritage and Sustainable Development aspects (Mecca et al. 2005). More research studies are needed to enhance the energy efficiency of Moroccan Ksourians architecture which is considered less complicated in terms of space distribution. Vernacular architecture of south Morocco represents the principle of climate-responsive architecture, which still lacks experimental validation and quantitative analysis. Thermal comfort does not only keep the inhabitants comfortable, it also limits the building's energy consumption. Detailed field studies on thermal efficiency in various bioclimatic zones of typical traditional vernacular dwellings have still not been carried out. The present study is dedicated to the investigation of thermal behavior of new configuration vernacular design inspired by the Ksours architecture, while treating the building envelope and architectural aspects at the same time. For this purpose, thermophysical experimental characterization has been carried out in order to identify the thermal and physical properties of the local earth and coating materials. Dynamic thermal Simulation is carried out in order to reveal the influence of orientation in traditional buildings on the thermal behavior and energy performance, in addition to developing the built mass structure, optimal building orientation, space planning, and availability of sunspace, building techniques, and materials for manufacturing and roofing aspects.

\section{Description of the case study}

In order to explore this issue closely, a case study is needed. The choice of the case was not easy. Morocco has exceptional wealth in terms of typologies and vernacular forms. In the end, the choice fell on the Amazigh ksours located in the south of Morocco, as a type of collective habitation situated in a particularly harsh climate. The choice of the city of Rissani is mainly attributed to its predictive value of the semi - arid climate of south of the country, which is characterized by a hot and dry weather, that is detrimental to thermal comfort during the summer. Is thus characterized by a warm and dry weather that is impacting to thermal comfort during the summer. Rissani's preference enables the interpretation of thermal activity in vernacular buildings to be established. The dwelling topology of this region are distinguished by an arbitrary, scattered and fragmented orientation, which recognizes the quantity of energy that can be used, the thermal comfort within such vernacular structures and the application of adapted materials to the climatic requirements (Mecca, 2007). 

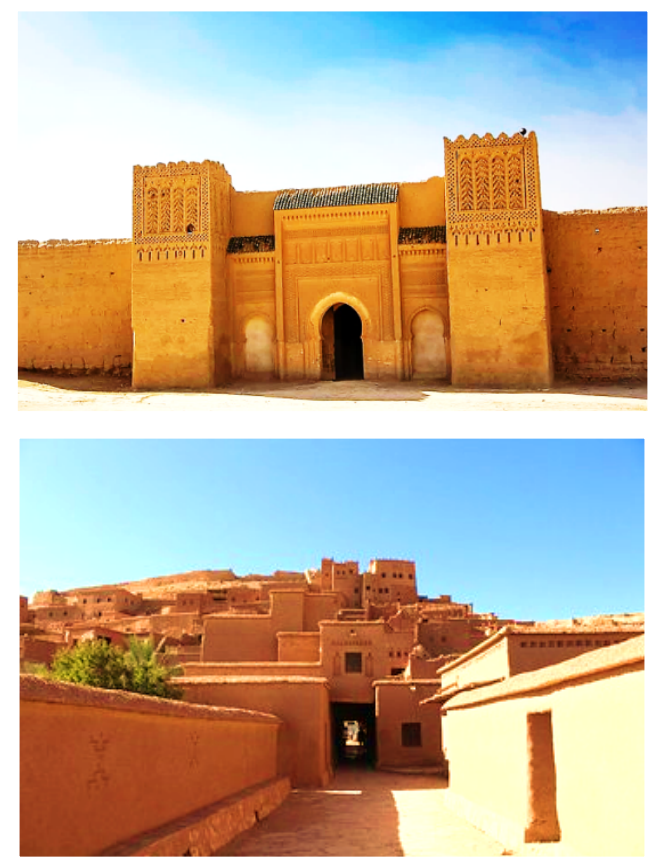

Fig. 1 Presentation of the studied "Ksar El Fida" in Rissani City

Figure 1 presents a description of the case study chosen for this research investigation which is "Ksar El Fida, the largest and oldest of the Alawi tafilalet ksours, situated about $4 \mathrm{~km}$ northeast of the city of Rissani. The Ksar is a popular format for the residents of the raid and desert cultures. It represents a typical urban type of fortified cities in these regions.

The (Ksar-Oasis) is an environmental ecosystem that facilitates occupation. From a morphological viewpoint, the ksar tends to be an adequately compact component, dominated by clay color, closely linked to the green space of the oasis (Djeradi, 2012). Originally, it is a collective granary which serves as a place for ensilage of cereals, olives, livestock products; it is also a safe place where valuables are secure. Among the causes that allow us to state this hypothesis of the functionality of the ksar: the fact that the southwestern region of Morocco and the Sahara in general are subject to climatic aridity aggravated by irregular rainfall that does not leave room for continuous food security and which makes the ksar a secure means of conservation.

\section{Mineralogical analysis of the Rissani earth and sample preparation}

\subsection{Mineralogical composition}

The mineralogical composition of the clay sample is determined by X-ray diffraction technology, which allows the determination of the different crystalline mineral phases present in the sample. The equipment used is the D8 Advance BRUKER AXS energy dispersive diffractometer (Dietel et al. 2017). The Figure 2 shows the diffraction diffractograms of the studied earth. The diffractogram of the Rissani earth samples shows that it is essentially composed of Quartz, Aluminosilicates and some traces of Pyrite and Illite. The presence of montmorillonite may cause some difficulties during the drying process, due to significant shrinkage and capillary retention.

\subsection{Mineralogical composition}

As shown in the Figure 3, the microstructure of the soil samples was observed and analyzed using the HITACHI S-3600N scanning electron microscope (SEM). SEM allows the surface morphology of the sample to be observed by scanning the surface with an electron beam and collecting the image formed. As the sample is non-conductive, the surface must be metalized by covering it with a thin layer of gold. There are two ways to achieve this where the sputtering was used for this study. This involves depositing atoms torn from a piece of metal (gold) by ionized argon in a vacuum fume hood part (Al Muskhtar et al. 2012).

\subsection{Particle size distribution analysis}

This involves determining the size and weight percentages of the different grain families. It consists of measuring the mass of material passing through the calibrated meshes of a sieve cloth according to EN 933-1 and 933-2. The sieves are superimposed by decreasing mesh and the mass of the material retained on each sieve is measured. This operation was carried out by vibrating the entire sieve column with mechanical agitation (Hall, \& Allinson 2009). The granulometric curve of the Rissani clay sample fits perfectly within the acceptance field defined by CRATerre, even if it is irregularly shaped: there is a strong increase for $200 \mu \mathrm{m}$ grains whereas for granulometric classes above $400 \mu \mathrm{m}$, the curve is almost horizontal. The granulometric curves show that the sample is mainly of fine soil origin (Fig. 4). It contains more than 10\% fines (particles passing through the $0.063 \mathrm{~mm}$ sieve). In addition, the soil must have a minimum of clay ensuring cohesion between the grains of the material during compaction (the percentage of the $2 \mu \mathrm{m}$ sieve passers-by must be greater than $10 \%$ ). The present soil verified this criterion since the percentage of the $2 \mu \mathrm{m}$ sieve passers-by $(0.002 \mathrm{~mm})$ exceeds $20 \%$. On the other hand, the studied soil meets the requirements of the earthquake-proof regulation for earth constructions (RPCT 2011).

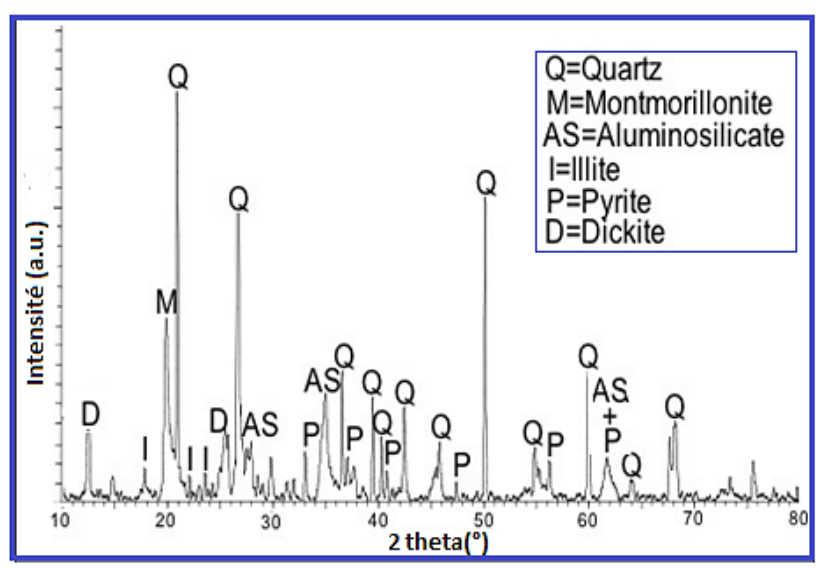

Fig. 2 X-ray diffractogram of Rissani Clay 
a)

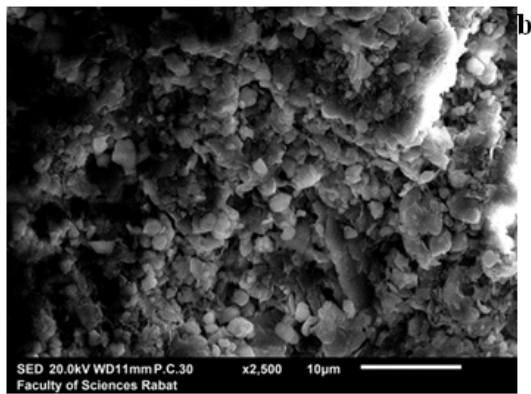

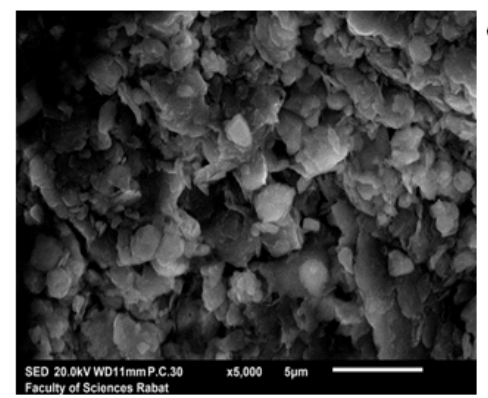

c)

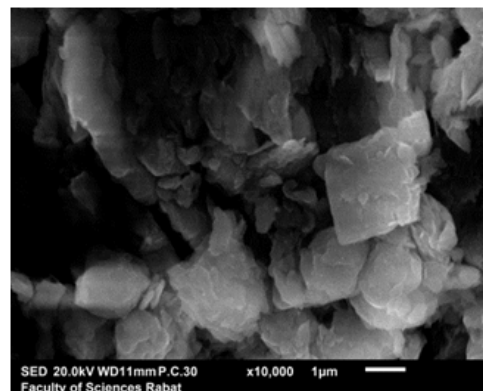

Fig. 3 Microscopic observation of Rissani earth (SEM) according to three enlargements a) x2500, b) x5000, c) x10000

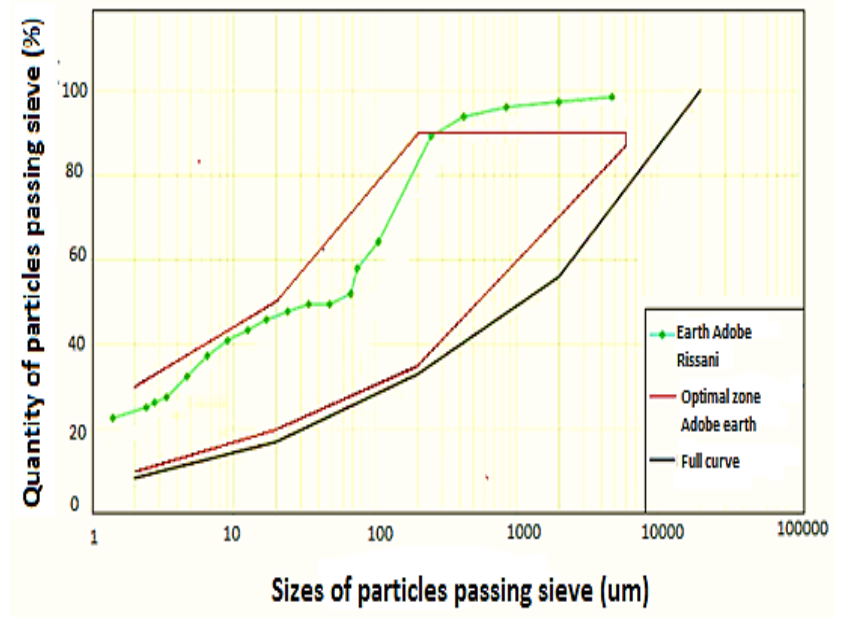

Fig. 4 Particle size distribution of the Rissani earth

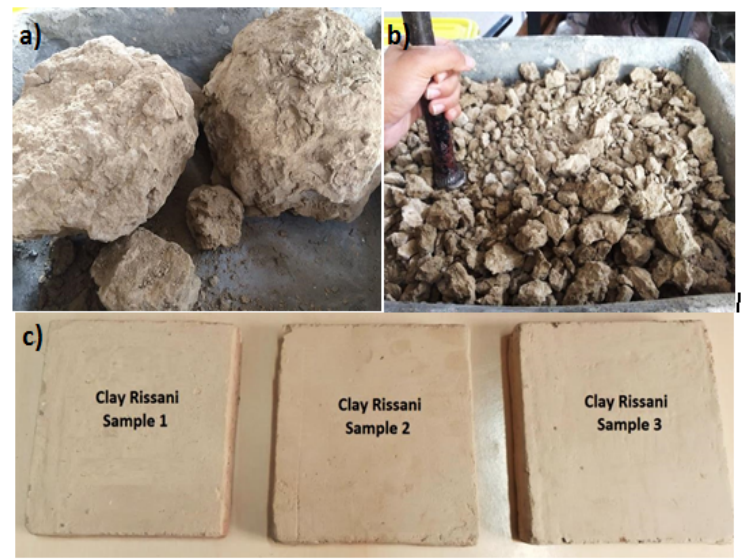

Fig. 5 preparation protocol of earth samples

\subsection{Samples preparation}

The characterized raw clay is extracted from the DraaTafilalet region (Errachidia province). Samples were collected during its reconstruction after the removal of an inner wall situated in Ksar El Fida. (Fig. 5-a). The extracted samples were then manually crushed with a hammer (Fig. 5-b) in order to obtain a raw powder (Fig. 5c). After, the clay underwent a granulometric analysis as shown in figure 5 . The mixture of the raw clay with a mass fraction of 0.25 of water is stirred by an agitator until a homogeneous paste is obtained. This paste is then poured into parallelepiped metal molds with dimensions of
$150 \times 150 \times 30 \mathrm{~mm}^{3}$. After the samples have been prepared, they were dried in ambient air for 72 hours, then in the oven at $45^{\circ} \mathrm{C}$ according to N FP 75-101 (French standards 1983) remove the water trapped inside. A daily measurement of the bulk mass of the studied samples have been carried out until a constant mass was obtained, the samples were wrapped in plastic film to eliminate any type of moisture absorption (El Azhary et al.2017).

\section{Experimental methods for thermal characterization}

\subsection{Guarded hot plate method}

The guarded hot plate method $\lambda$-Meter EP500e (Fig. 6) is used in order to estimate the thermal conductivity $\lambda$ (W/m.K) of the characterized samples according to (E.N. ISO, 8302,1991$)$. It has a low uncertainty of $2 \%$. It is based on the principle of placing the characterized sample with dimensions $150 \times 150 \mathrm{~mm}^{2}$ between a hot and a cold plate. A uniform heat flow $\varphi$ is generated through the sample and the temperature evolution of the hot and cold sides $\mathrm{T}_{\mathrm{h}}$ and $\mathrm{T}_{\mathrm{c}}$ respectively are recorded (Hammerschmidt.2002).
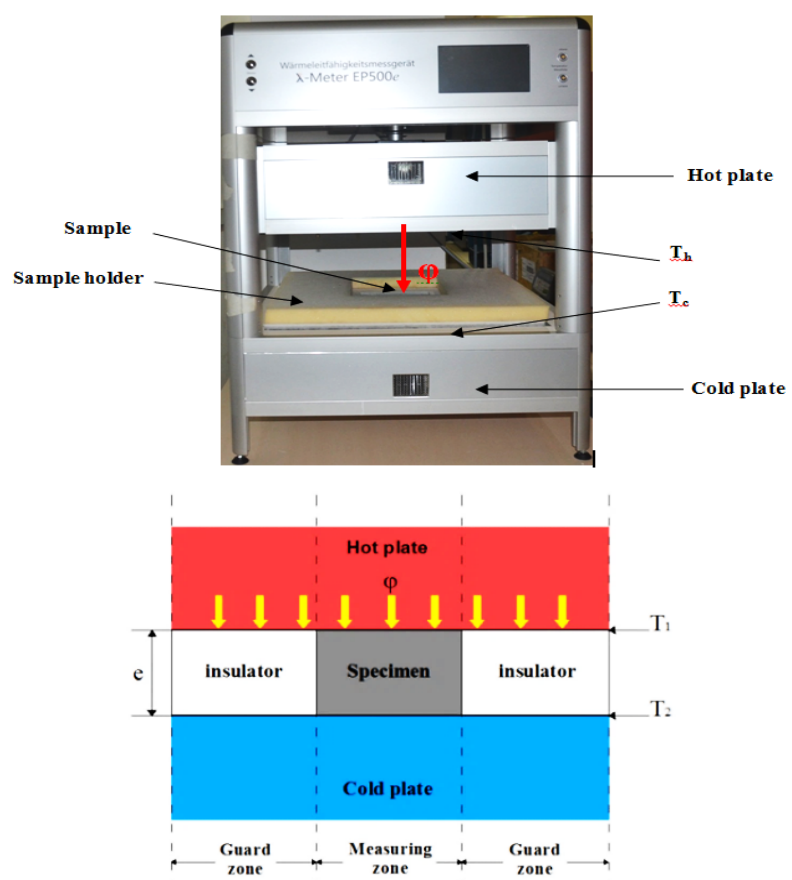

Fig. 6 Experimental and schematic device of the guarded hot plate method 
Before starting the measurement, the sample both sides are grounds with an ultrasonic gel to achieve high flatness and thus avoid contact heat resistance. Once steady state is established, the thermal conductivity can be measured from the heating power $\varphi$, the sample thickness e, the measuring surface $\mathrm{S}$ and the temperature difference between the two plates $\Delta \mathrm{T}$.

$\lambda=\frac{\varphi \times \mathrm{e}}{\mathrm{S} \times \Delta \mathrm{T}}$

\subsection{Hot plate method in the steady-state regime}

The hot plate method in a steady-state regime allows us to determine the thermal conductivity of building materials. This technique is based on the principle of producing a uniform heat flow by means of a heating element of $150 \times 150 \times 0.2 \mathrm{~mm}^{3}$ and an electrical resistance of $\mathrm{Re}=$ $37.89 \Omega$, placed between the characterized sample and the reference sample (polyethylene foam)(Jannot et al. 2016). The upper faces of the two samples are kept in contact with two isothermal aluminum blocks (Fig 7).

The temperatures in the center of the heating element, of the characterized sample and of the reference sample $\mathrm{T}_{0}, \mathrm{~T}_{1}$, and $\mathrm{T}_{2}$ respectively are measured by type $\mathrm{K}$ thermocouples with a measurement uncertainty of approximately $+/-0.6^{\circ} \mathrm{C}$ (Ouakarrouch et al.2020).

The heat flow assumed to be unidirectional is divided into two parts, each passing through the characterized sample of thickness es and the reference sample of thickness ep. Lateral thermal losses and contact heat resistance are neglected. Once the stationary regime has been established, the Fourier's law allows the determination of the thermal conductivity (Herrero et al.) according to the equation 3 .

$\phi_{\mathrm{T}}=\phi_{\mathrm{S}}+\phi_{\mathrm{P}}=\frac{\mathrm{U}^{2}}{\mathrm{R}_{\mathrm{e}} \mathrm{S}}$

$\mathrm{U}, \mathrm{Re}$ and $\mathrm{S}$ denote the applied voltage, the electrical resistance and the heating element surface respectively.

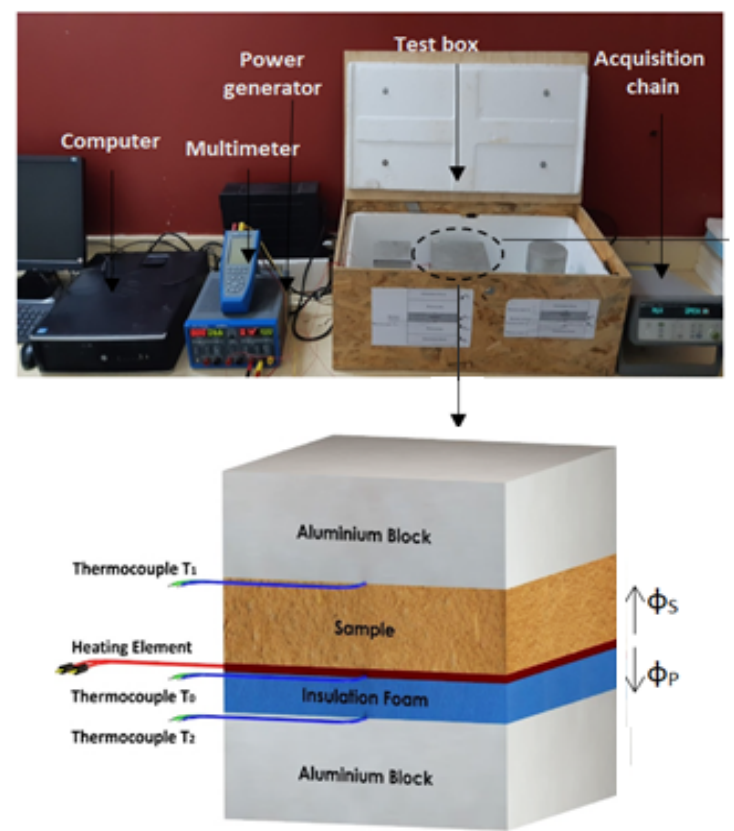

Fig. 7 Experimental and schematic device of the hot plate method in a steady-state regime

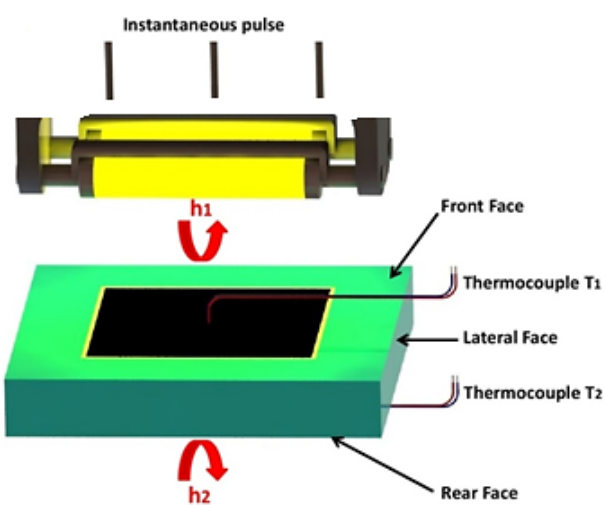

Fig. 8 Schematic device of the flash method

Table 1

Parameter values for the experimental measurements

\begin{tabular}{cccccc}
\hline $\begin{array}{c}\text { Voltage } \\
(\mathrm{V})\end{array}$ & $\begin{array}{c}\text { Electrical } \\
\text { resistance } \\
(\Omega)\end{array}$ & $\begin{array}{c}\mathrm{e}_{\mathrm{s}} \\
(\mathrm{mm})\end{array}$ & $\begin{array}{c}\mathrm{e}_{\mathrm{p}} \\
(\mathrm{mm})\end{array}$ & $\begin{array}{c}\lambda_{\mathrm{p}} \\
(\mathrm{W} / \mathrm{m} \cdot \mathrm{K})\end{array}$ & $\begin{array}{c}\mathrm{S} \\
\left(\mathrm{m}^{2}\right)\end{array}$ \\
\hline 14.101 & 37.89 & 30 & 9.6 & 0.043 & 0.0225 \\
\hline
\end{tabular}

The conductivity of the characterized sample $\lambda \mathrm{S}$ is calculated using the equation 3 .

$\lambda_{\mathrm{S}}=\frac{\mathrm{e}_{\mathrm{S}}}{\mathrm{T}_{0}-\mathrm{T}_{1}} \times\left[\frac{\mathrm{U}^{2}}{\mathrm{R}_{\mathrm{e}} \mathrm{S}}-\frac{\lambda_{\mathrm{P}}}{\mathrm{e}_{\mathrm{P}}} \times\left(\mathrm{T}_{0}-\mathrm{T}_{2}\right)\right]$

es is the thickness of the characterized sample, $\lambda_{\mathrm{P}}$ and $\mathrm{eP}_{\mathrm{P}}$ are respectively the thermal conductivity and the thickness of the polyethylene foam. Table 1 summarizes the various parameters required for the experimental measurements.

\subsection{Flash Method}

The flash method allows to determine the thermal diffusivity a $\left(\mathrm{m}^{2} / \mathrm{s}\right)$ of the materials in the transient regime, it consists of sending a luminous flow for a short time $(t=8 \mathrm{~s})$ through the front face of the characterized sample, and to record the temperature evolution of the rear face using a thermocouple type $\mathrm{K}$. The characterized sample is tinted in black to absorb the entire luminous flux. It is then surrounded by an extruded polystyrene sample holder and the interaction between the two is sealed with glass wool (Fig. 8).

$$
\begin{aligned}
& \mathrm{F}(\mathrm{p})=\frac{1-\mathrm{e}^{-\mathrm{p} \cdot \mathrm{t}_{\mathrm{d}}}}{\mathrm{p} \cdot \mathrm{t}_{\mathrm{d}}} ; \\
& \mathrm{b}_{\mathrm{i} 1}=\frac{\mathrm{h}_{1} \mathrm{e}}{\lambda} ; \\
& \mathrm{b}_{\mathrm{i} 2}=\frac{\mathrm{h}_{2} \mathrm{e}}{\lambda} ; \\
& \mathrm{T}_{\max }=\frac{\phi_{0}}{\rho c \mathrm{e}}
\end{aligned}
$$

The mathematical modeling of the flash method makes it possible to determine the thermal diffusivity, and this is the case of several researchers who have developed classical estimation models, namely Parker (Parker et al. 1961) (Degiovanni et al. 1979). Within the framework of 
this work, a new mathematical model development of the flash method will be carried out under the hypothesis of unidirectional heat transfer, taking into account heat losses on both sides of the sample. Therefore we can write:

$$
\left\{\begin{array}{l}
\frac{\partial^{2} \mathrm{~T}(\mathrm{x}, \mathrm{t})}{\partial \mathrm{x}^{2}}=\frac{1}{\mathrm{a}} \frac{\partial \mathrm{T}}{\partial \mathrm{t}}=0 \\
\left.\frac{\partial \mathrm{T}(\mathrm{x}, \mathrm{t})}{\partial \mathrm{x}}\right|_{\mathrm{x}=0}=-\mathrm{h}_{1} \cdot \mathrm{T}(0, \mathrm{t})+\phi_{0} \cdot \mathrm{f}(\mathrm{t}) \\
\left.\frac{\partial \mathrm{T}(\mathrm{x}, \mathrm{t})}{\partial \mathrm{x}}\right|_{\mathrm{x}=\mathrm{e}}=\mathrm{h}_{2} \cdot \mathrm{T}(\mathrm{e}, \mathrm{t}) \\
\mathrm{f}(\mathrm{t})= \begin{cases}\frac{1}{\mathrm{t}_{\mathrm{d}}} & , \\
0 & , \quad \mathrm{t}_{\mathrm{d}} \leq \mathrm{t} \leq \mathrm{t}_{\mathrm{d}}\end{cases} \\
\mathrm{T}(\mathrm{x}, 0)=0
\end{array}\right.
$$

Hence: $\mathrm{a}$ is the thermal diffusivity, $\mathrm{h}_{1}$ and $\mathrm{h}_{2}$ are the global heat exchange coefficients on both sides of the sample, is the amount of heat absorbed at the front limit $(x=0), f(t)$ is the time dependence of the heat generation (Standard, E1461-13). The product refers to the finished pulse of a flash duration td. Laplace's transformation of equation (4) leads to the following equation:

$$
\begin{aligned}
& \theta(e, p)=\frac{j \cdot T_{\max } \cdot F(p)}{\left[\operatorname{Cosh}(\sqrt{j p})\left(b_{i 1}+b_{i 2}\right)+\operatorname{Sinh}(\sqrt{j p})\left[\frac{j p+\left(b_{i 1} \cdot b_{i 2}\right)}{\sqrt{j p}}\right]\right]} \\
& \text { with }: j=\frac{e^{2}}{a}
\end{aligned}
$$

$F(p)$ is the Laplace transform of $f(t)$, e is the sample thickness, bi1 and bi2 are the Biot numbers, Tmax is the adiabatic limit temperature.

This equation has been analytically solved in the time space and then numerically inverted using the GaverStehfest algorithm to derive the theoretical temperature of the back face according to the following parameters: e, Tmax, a, bi $i_{1}, b_{2}$, and $t$. The latter being simultaneously estimated from experimental data. The optimal values of these parameters are obtained by minimizing the squared distance $\mathrm{M}$ between the theoretical model resulting from the numerical inversion and the experimental thermogram (Eq. 6):

$$
\mathrm{M}\left(\mathrm{e}, \mathrm{T}_{\mathrm{ma}}, \mathrm{a}, \mathrm{b}_{\mathrm{i} 1}, \mathrm{~b}_{\mathrm{i} 2}\right)=\sum_{(\mathrm{i}=1)}^{\mathrm{N}}\left[\mathrm{T}_{\exp }\left(\mathrm{t}_{\mathrm{i}}\right)-\mathrm{T}_{\mathrm{th}}\left(\mathrm{e}, \mathrm{T}_{\mathrm{ma}}, \mathrm{a}, \mathrm{b}_{\mathrm{i} 1}, \mathrm{~b}_{\mathrm{i} 2}, \mathrm{t}_{\mathrm{i}}\right)\right]^{2}
$$

The Nelder-Mead algorithm (Nelder and Mead. 1965) has been implemented to solve the minimization problem in equation (6). Finally, a special script of this numerical model has been developed in Mathematica language.

\section{Thermal dynamic simulation}

\subsection{Description of the studied building set}

The current study seeks to identify the energy efficiency of a vernacular housing in the Ksar El Fida area of Rissani, an urban typology characterized by a light housing architecture and a historical landscape full of valuable cultural attitudes and representing an illustration of neighborhood villages made of earthen bricks (Terrasse, 1938).

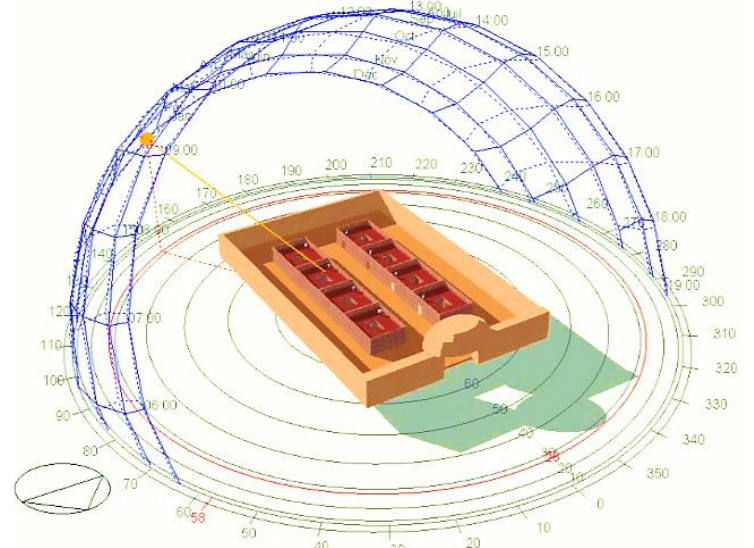

Fig. 9 3D View of the studied building set

Figure 9 is an illustration of a vernacular housing construction that groups together eight houses of identical construction. The building assembly is protected by a 3meter-high external enclosure that prevents extreme temperature variations (El Azhary et al. 2019).

A high degree of vertical and horizontal compactness marks the urban characteristics of this style of construction. Consequently, in winter, the surface area is marginally reduced and winds blow hard. As seen in Figure 10, each building covers an area of $80 \mathrm{~m}^{2}$, which gives a volume of $240 \mathrm{~m}^{2}$. Each building is implemented in the form of a ground floor with a maximum height of 3.03 $\mathrm{m}$, the windows dimensions are $(1.20 \mathrm{~m} \times 1.40 \mathrm{~m})$ according to the various structural elements.

The open-air courtyard "patio" is organized throughout the different elements of the building. Its design focuses on regulating temperatures and providing light and sun sources. The patio provides a vital area for the articulation of the building's various sections, both inside and outside terraces, which can be reached by masonry or wooden stairs (Delaigue, et al. 2015). Occupying $17.46 \%$ of the open façade to the patio $(32.34 \%$ of the floor area) representing a full-scale open courtyard where the different elements of the building are interconnected. Its design is based on temperature adjustment and the use of light and solar radiation sources. The patio around which the kitchen and bedrooms are designed, with its trough-shaped configuration, it represents the greatest protection for a private open space toward extreme heat, dust-laden wind gusts and sandstorms.

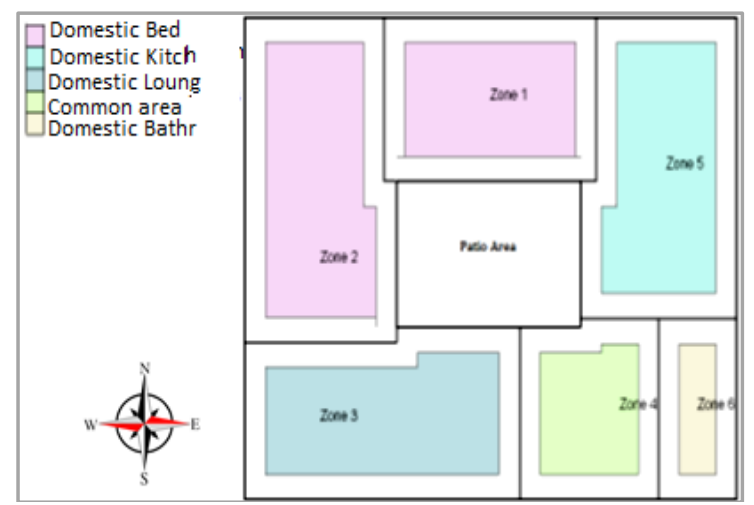

Fig. 10 Spatial distribution of typical residential components 
Table 2

Monthly normal climate of Rissani City (meteonorm 2010)

\begin{tabular}{|c|c|c|c|c|c|c|c|c|c|c|c|c|c|}
\hline Months & & Jan & Feb & Mar & Apr & May & Jun & Jul & Aug & Sep & Oct & Nov & Dec \\
\hline \multirow{4}{*}{$\begin{array}{l}\text { Dry Bulb } \\
\text { Temp. }\left[{ }^{\circ} \mathrm{C}\right]\end{array}$} & Abs. Max. & 28.9 & 34.3 & 36.2 & 39.6 & 44.4 & 45.8 & 49.0 & 47.0 & 44.8 & 38.6 & 35.2 & 28.9 \\
\hline & Abs. Min. & -2.3 & -3.0 & 0.4 & 2.8 & 6.8 & 9.4 & 12.1 & 12.8 & 10.0 & 1.1 & 0.0 & -1.6 \\
\hline & Mean Max. & 18.4 & 19.9 & 22.3 & 23.7 & 27.5 & 31.3 & 36.8 & 36.5 & 32.5 & 27.5 & 22.2 & 18.7 \\
\hline & Mean Min. & 5.9 & 7.6 & 9.4 & 11.0 & 13.8 & 16.3 & 19.9 & 20.1 & 18.2 & 14.7 & 10.4 & 6.5 \\
\hline Precipita & Mean & 32.2 & 37.9 & 37.8 & 38.8 & 23.7 & 4.5 & 1.2 & 3.4 & 5.9 & 23.9 & 40.6 & 31.4 \\
\hline Rainy days & Mean & 7.6 & 6.8 & 7.5 & 7.7 & 4.8 & 1.2 & 0.6 & 1.2 & 2.8 & 5.5 & 6.6 & 6.5 \\
\hline $\mathrm{RH}[\%]$ & Mean & 66 & 65 & 59 & 58 & 58 & 52 & 44 & 47 & 53 & 54 & 68 & 68 \\
\hline Sun. Hours & Mean & 220.6 & 209.4 & 247.5 & 254.5 & 287.2 & 314.5 & 335.2 & 316.2 & 263.6 & 245.3 & 214.1 & 220.6 \\
\hline
\end{tabular}

\subsection{Climate analysis of Rissani City}

The Rissani City linked to the province of Errachidia in the region of Draa tafilalet is located in southeastern Morocco, $31^{\circ} 55^{\prime} 53^{\prime \prime}$ north latitude and $4^{\circ} 25^{\prime} 35^{\prime \prime}$ west longitude. It drops to an altitude of $1039 \mathrm{~m}$. The high temperatures range from $28.5^{\circ} \mathrm{C}$ to $40^{\circ} \mathrm{C}$ per year. Maximum annual temperatures range from $28.5^{\circ} \mathrm{C}$ to $40^{\circ} \mathrm{C}$. The prevailing climate in the province of Errachidia, as described in this study, is generally characterized by a cold winter, dry and hot summer climate (Fig. 11). The city's climate is favorable all year round with an average temperature of around $18^{\circ} \mathrm{C}$, an annual temperature range of $8^{\circ} \mathrm{C}$ and a moderate humidity of $57.5 \%$ (Meteonorm 2010). In general, the climate of southern Morocco maintains heating needs during winter and cooling needs during summer, allowing heat exchange temperatures to approach the cooling point and average annual summer temperatures of $35^{\circ} \mathrm{C}$. Weather moderation as a whole allows most of needs to be achieved naturally, especially in the residential sector (Aboul Naga el al. 2001).

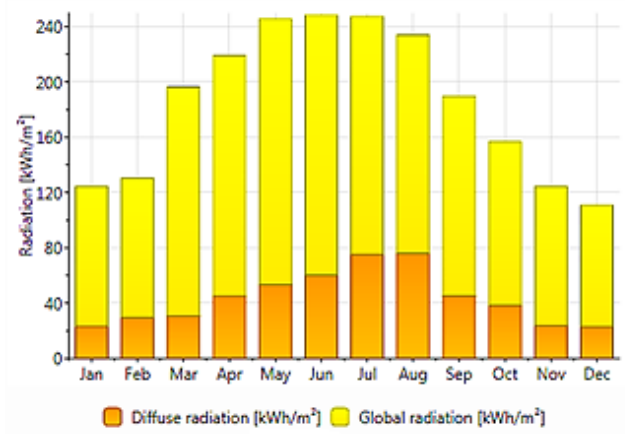

(a)

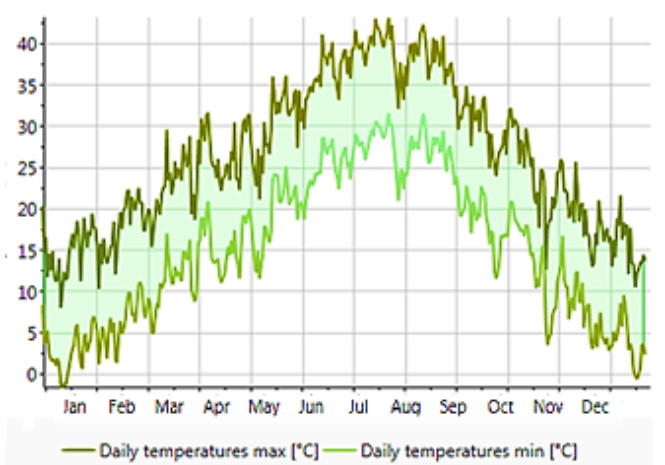

(b)

Fig. 11 Annual weather data of Rissani City (a) annual solar radiation (b) maximum and minimum daily temperatures
It is also observed that even during rainy months; relative humidity is low and reaches a limit of $65 \%$. The mean monthly hours of sunshine are distinguished by a maximum of $335.2 \mathrm{~h}$ during July and a minimum of $220.3 \mathrm{~h}$ during January. This parameter, even with a difference of almost 115 hours, can indeed be considered relatively homogeneous, making Rissani a sunny city most of the year. It is clear that temperatures and precipitation highlight the disappearance of intermediate seasons (or intense shortness), which divided the year into two main intense seasons, one hot and one cold (Laaroussi et al 2016).

\subsection{Description of the building envelope}

The building envelope plays a significant role in providing thermal insulation between the indoor and outdoor climates, it operates as a heat accumulator and as an indoor and outdoor air collector, hence why the choice of building materials display as an essential factor in ensuring the building's required energy output. An efficient selection of construction materials decreases the heat exchange temperatures inside building areas greatly. The exterior facade is considered as the core element of the building's conception. The studied building benefits from two types of natural ventilation, namely the horizontal ventilation produced by the windows and the vertical ventilation created by the courtyard opening, reflecting an efficient natural ventilation system in dry zones, the ability of which is known to maintain a good air temperature inside the building so that heating is reduced in the summer. The building selected for experimentation has an operable window providing intensive ventilation. Common halls and stairs are ventilated through a natural evacuation duct of at least $\left(0.5 \times\right.$ vol. of the room $\left(\mathrm{m}^{3} / 3600\right)$ $\mathrm{m}^{2}$ ). As shown in Figure 3, openings are provided in the interior patio elevations. The opening area of the exterior surface is $3.88 \mathrm{~m}^{2}$. When the residential density is 0.14 pers $/ \mathrm{m}^{3}$, the natural ventilation rate including penetration is approximately $36 \mathrm{~m}^{3} / \mathrm{h} /$ pers. No heating or cooling system is provided. As shown in Figure 10, each building is divided into six thermal zones according to their activities. The average number of occupants corresponding to the degree of residential occupation of the occupants of each house is equivalent to five individuals.

\subsection{Parameterization}

A fixed energy consumption schedule, defined on the basis of the traditional culture and lifestyle of the region 
inhabitants, is used in all simulations (holidays, working hours, etc.). For each combination of evaluated parameters, a simulation of thermal activity and thermal comfort was conducted. The metabolic rate frequency is 1.5 between 08:00 and 23:00, and 1 between 23:00 and 08:00. The thermal resistance of clothing is equivalent to 0.5 clo (summer clothing). The metabolic activity level is 1.5 puts from $08: 00$ to $23: 00$, and 1 puts from 23:00 to 08:00. The thermal resistance of clothing is equal to 0.5 clo (summer clothing) and a relative air velocity of $0.1 \mathrm{~m} / \mathrm{s}$. The rate of air change is estimated to be $0.6 \mathrm{vol} / \mathrm{h}$, yet it is supposed that windows are open during the mornings and after $6 \mathrm{pm}$ in the evenings. In this investigation, Design builder is used as simulation software, it is simulation systems devoted to the measurement of the thermal efficiency of multi-zone buildings thermal performance. Design builder is adapted to modular architectures of new components and simulation problems in completely different domains using energy simulation based on the EnergyPlus interface (V.5.0.0.105). It employs several forms of multiple and complex mathematical equations to accurately solve such a system and, since these equations represent highly interconnected heat transfer processes, simultaneous solution techniques are needed if production prediction is to be both reliable and the spatial and temporal integrity of the modeled system is to be maintained. The thermal performances were measured in compliance with ASHRAE standard 55 (ASHRAE, 2010).

\section{Results}

\subsection{Thermophysical characterization}

\subsubsection{Bulk density}

The knowledge of the dimensions and masses of the dry samples allowed us to easily determine their apparent densities (Schatz \& Simmons 1972), which are presented in the Table 3.

Table 3

Bulk density of the different samples

\begin{tabular}{cccc}
\hline & $\begin{array}{c}\text { Dimensions } \\
\left(\mathrm{mm}^{3}\right)\end{array}$ & $\begin{array}{c}\text { Dry mass } \\
(\mathrm{g})\end{array}$ & $\begin{array}{c}\text { Bulk density } \\
\left(\mathrm{Kg} / \mathrm{m}^{3}\right)\end{array}$ \\
\hline Sample 1 & $15.05 \times 14.96 \times 3.03$ & 1154 & 1691.6 \\
Sample 2 & $15.02 \times 14.98 \times 3.00$ & 1152 & 1706.7 \\
Sample 3 & $15.07 \times 15.00 \times 3.02$ & 1158 & 1696.2 \\
\hline \multicolumn{4}{c}{ Mean value of Bulk density } \\
\hline
\end{tabular}

Table 4

Thermal conductivity measurement using the guarded hot plate method

\begin{tabular}{lccc}
\hline Measuring conditions & Sample & Sample & Sample \\
& 1 & 2 & 3 \\
\hline Thickness $(\mathrm{cm})$ & 3.03 & 3 & 3.02 \\
Pressure $(\mathrm{Pa})$ & 1000 & 1000 & 1000 \\
Temperature $\left({ }^{\circ} \mathrm{C}\right)$ & 23 & 23 & 23 \\
Temperature difference $\left({ }^{\circ} \mathrm{C}\right)$ & 15 & 15 & 15 \\
Thermal conductivity & 0.658 & 0.657 & 0.659 \\
(W/m.K) & & & 0.658 \\
\hline Mean value (W/m.K) & & & \\
\hline
\end{tabular}

The bulk density of the three samples was obtained by measuring their dimensions with a high-precision caliper and weighing their masses with an electronic balance. Table 3 summarizes the various parameters measured.

\subsubsection{Thermal conductivity}

\section{a) Guarded hot plate method}

In the steady state regime, the samples thermal conductivity was measured every 30 seconds and the standard deviation of the previous 30 values from $\lambda$ (for the last 15 minutes) is $0.01 \mathrm{~W} / \mathrm{m} . \mathrm{K}$. The measurements time was taken for 4 hours for each test. The obtained results are shown in Table 4.

The final value of thermal conductivity retained for this study is that of the hot plate, due to the fact that this technique of thermal characterization is standardized ISO-8302 and has high measurement accuracy with a low uncertainty of about $0.5 \%$.

\section{b) Hot plate method in the steady-state regime}

Three sets of tests were carried out with each sample to verify the reproducibility of the procedure and to statistically ensure the validity of the test. The results obtained and the corresponding measurement errors are shown in Table 5. These results were stopped by adopting specific methodology, such that the system is considered to have reached steady state only if the measured temperatures have stabilized for a period of at least 10 minutes (Jannot et al. 2011).

\subsubsection{Thermal diffusivity}

The thermal diffusivity of all the processed samples is estimated from the experimental thermograms obtained by the Flash method. The results obtained by the Parker model, the Degiovanni model (Degiovani et al.1979) and the complete model are presented in Table 5. The complete model, gives three parameters: the thermal diffusivity "a", the actual heat flow "Øo" through the sample and the convective exchange coefficient " $\mathrm{h}$ " across both sides of the sample. The identification of these three parameters is based on the minimization of the quadratic error between the two theoretical and experimental curves by taking into account all the recorded points of the experimental thermogram (Lim et al. 2009).

Table 5

Thermal conductivity measurement using Steady-state regime

\begin{tabular}{lccccc}
\hline $\begin{array}{l}\text { Measurement } \\
\text { series }\end{array}$ & $\lambda_{\mathrm{T} 1}$ & $\lambda_{\mathrm{T} 2}$ & $\lambda_{\mathrm{T} 3}$ & $\lambda_{\mathrm{m}}$ & $\frac{\Delta \lambda}{\lambda_{\text {mean }}}(\%)$ \\
\hline Sample 1 & 0.645 & 0.641 & 0.642 & 0.643 & 0.5 \\
Sample 2 & 0.638 & 0.637 & 0.640 & 0.638 & 0.5 \\
Sample 3 & 0.639 & 0.641 & 0.644 & 0.641 & 0 \\
\hline \multicolumn{5}{l}{ Mean value of thermal conductivity } & 0.641 \\
\hline
\end{tabular}


Table 6

Thermal diffusivity measurement using Flash method

\begin{tabular}{|c|c|c|c|c|c|c|c|}
\hline \multirow{2}{*}{$\begin{array}{l}\text { Measurement } \\
\text { series }\end{array}$} & \multicolumn{3}{|c|}{ Parker Model } & \multicolumn{2}{|c|}{ Degiovanni Model } & \multicolumn{2}{|c|}{ Complet Model } \\
\hline & Test & a. $10^{-7}\left(\mathrm{~m}^{2} \cdot \mathrm{s}^{-1}\right)$ & $\frac{\Delta \mathrm{a}}{\mathrm{a}_{\text {mean }}}(\%)$ & $\begin{array}{l}\text { a. } 10^{-7} \\
\left(\mathrm{~m}^{2} \cdot \mathrm{s}^{-1}\right)\end{array}$ & $\frac{\Delta \mathrm{a}}{\mathrm{a}_{\text {mean }}}(\%)$ & $\begin{array}{l}\text { a. } 10^{-7} \\
\left(\mathrm{~m}^{2} \cdot \mathrm{s}^{-1}\right)\end{array}$ & $\frac{\Delta \mathrm{a}}{\mathrm{a}_{\text {mean }}}(\%)$ \\
\hline \multirow[t]{4}{*}{ Sample 1} & 1 & 3.49 & 0.87 & 3.25 & 0 & 3.38 & 0.98 \\
\hline & 2 & 3.45 & 0.30 & 3.27 & 0.61 & 3.32 & 0.80 \\
\hline & 3 & 3.44 & 0.58 & 3.23 & 0.62 & 3.34 & 0.20 \\
\hline & Mean value & 3.46 & & 3.25 & & 3.35 & \\
\hline \multirow[t]{4}{*}{ Sample 2} & 1 & 3.42 & 0.10 & 3.23 & 0.31 & 3.29 & 0.41 \\
\hline & 2 & 3.40 & 0.68 & 3.28 & 1.22 & 3.30 & 0.10 \\
\hline & 3 & 3.45 & 0.77 & 3.21 & 0.93 & 3.32 & 0.50 \\
\hline & Mean value & 3.42 & & 3.24 & & 3.30 & \\
\hline \multirow[t]{4}{*}{ Sample 3} & 1 & 3.48 & 0.77 & 3.31 & 0.81 & 3.38 & 0.10 \\
\hline & 2 & 3.45 & 0.10 & 3.29 & 0.20 & 3.36 & 0.50 \\
\hline & 3 & 3.43 & 0.68 & 3.25 & 1.03 & 3.39 & 0.39 \\
\hline & Mean value & 3.45 & & 3.28 & & 3.38 & \\
\hline
\end{tabular}

Table 7

Calculation results of thermal capacity.

\begin{tabular}{|c|c|c|c|c|}
\hline & $\rho\left(\mathrm{Kg} / \mathrm{m}^{3}\right)$ & $\lambda_{\mathrm{m}}(\mathrm{W} / \mathrm{m} . \mathrm{K})$ & a. $10^{-7}\left(\mathrm{~m}^{2} \cdot \mathrm{s}^{-1}\right)$ & $\mathrm{c}_{\mathrm{p}}(\mathrm{J} / \mathrm{kg} \cdot \mathrm{K})$ \\
\hline Sample 1 & 1691.6 & 0.658 & 3.35 & 1161.13 \\
\hline Sample 2 & 1706.7 & 0.657 & 3.30 & 1166.52 \\
\hline Sample 3 & 1696.2 & 0.659 & 3.38 & 1153.00 \\
\hline \multicolumn{4}{|c|}{ Mean value of thermal conductivity } & 1160.22 \\
\hline
\end{tabular}

Table 8

Calculation results of thermal capacity.

\begin{tabular}{|c|c|c|c|c|c|c|}
\hline Component & Material & $\begin{array}{l}\text { Thickness } \\
\text { (cm) }\end{array}$ & $\begin{array}{l}\text { Conductivity } \\
\text { (W/m.K) }\end{array}$ & $\begin{array}{l}\text { Density } \\
\left(\mathrm{Kg} / \mathrm{m}^{3}\right)\end{array}$ & $\begin{array}{c}\text { Specific heat } \\
(\mathrm{J} / \mathrm{Kg} \cdot \mathrm{K})\end{array}$ & Reference \\
\hline \multirow[t]{3}{*}{ External wall } & Gypsum Plaster & 2 & 0.520 & 1196.3 & 772.7 & $\begin{array}{c}\text { (Ouakarrouch et al. } \\
2020)\end{array}$ \\
\hline & Adobe (Rissani) & 60 & 0.658 & 1698.2 & 1160.2 & \\
\hline & Coating clay- straw & 2 & 0.263 & 1544 & 595.6 & $\begin{array}{c}\text { (El.Azhary et al. } \\
\text { 2017) }\end{array}$ \\
\hline \multirow{5}{*}{ Roof } & Reed & 1 & 0.88 & 600 & 1256 & (RTCM 2012) \\
\hline & Wood & 6.5 & 0.134 & 436 & 2382.5 & $\begin{array}{c}\text { (Ouakarrouch et al. } \\
\text { 2019) }\end{array}$ \\
\hline & Plastic protection & 0.1 & 0.2 & 1050 & 1500 & \\
\hline & Unfired clay & 4.5 & 0.58 & 1800 & 772 & $\begin{array}{c}\text { (El Azhary et al. } \\
\text { 2018) }\end{array}$ \\
\hline & Floor tiles & 2 & 0.8 & 2000 & 800 & (RTCM 2012) \\
\hline Window & Simple glazing & 0.6 & 0.954 & 2356 & 720 & (RTCM 2012) \\
\hline Door & Red Wood & 3 & 0.134 & 436 & 2382.5 & $\begin{array}{c}\text { (Ouakarrouch et al. } \\
\text { 2019) }\end{array}$ \\
\hline
\end{tabular}




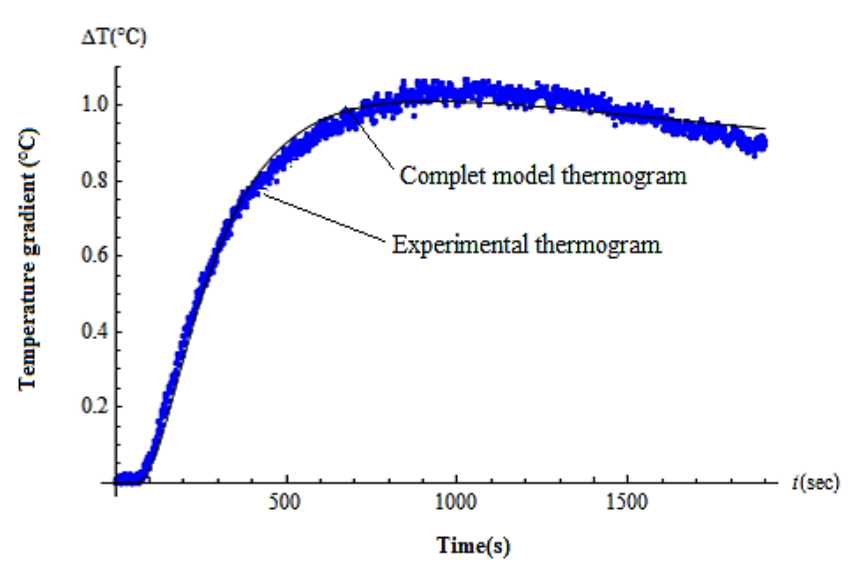

Fig. 12 Comparison between theoretical and experimental curves

From these results, it can be found that the thermal diffusivity obtained values by the Parker model vary greatly from those obtained by the complete model; as an effect, Parker considers that, in the thermal diffusivity calculation, only one point of the thermogram corresponds to the half-lift time of the thermogram, which does not represent the convective heat value of the thermogram. (Parket et al..1961). On the other hand, the results obtained by Degiovanni's model are close to those of the full model, because Degiovanni proposes the estimation of thermal diffusivity by a model based on four different points of the experimental thermogram, taking into account (in part) in an implicit way the effect of the coefficient " $h$ ". It is reported that the measurement uncertainty for the experimental thermal diffusivity values obtained does not exceed $1 \%$ for all samples tested, which shows the reliability of the results obtained by the Flash method (Raefat et al.2017).

\subsubsection{Thermal heat capacity}

Although the bulk density, thermal conductivity and thermal diffusivity, which characterize the conductive heat transfer within the material, have been measured, it is sufficient to deduce the heat capacity using the equation 7 .

$$
\mathrm{c}_{\mathrm{p}}=\frac{\lambda}{\rho . \mathrm{a}}
$$

Table 6 summarizes the experimental results obtained and the calculation results for the three samples tested. A mean value of used clay is $1128.5 \mathrm{~J} / \mathrm{kg} . \mathrm{K}$.

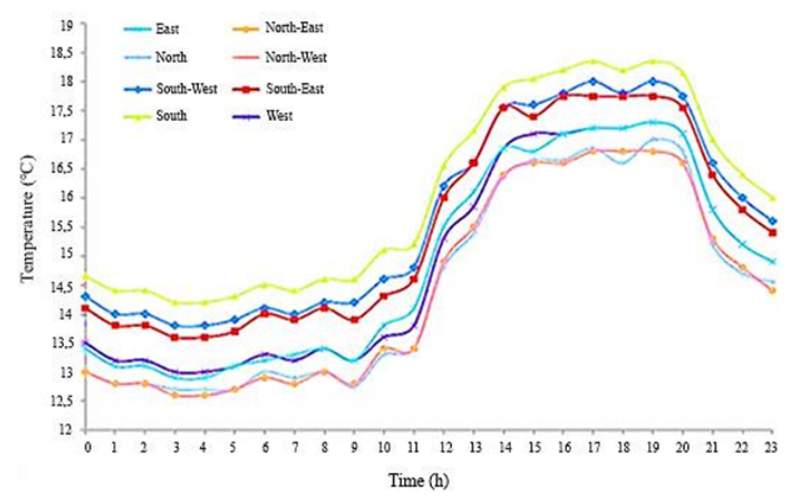

Fig. 13 variation of indoor temperatures according to different orientations during the winter season

\subsection{Thermal Dynamic Simulation results}

The exterior walls composed from Rissani studied earthen adobe of $60 \mathrm{~cm}$ in thickness with an external layer coating consisting of straw-clay and an interior coating of plaster. The thermo physical properties (Thermal conductivity, $\lambda$ $(\mathrm{W} / \mathrm{m} . \mathrm{K})$, density, $\rho\left(\mathrm{kg} / \mathrm{m}^{3}\right)$, and specific heat capacity $\mathrm{c}_{\mathrm{p}}$ (J/kg.K) used in the $U$ calculation for each layer of the building envelope were presented in Table 7, which describes the thermal properties of different layers of materials that constitute the building exterior roof and exterior wall.

The simulation results and analysis concerns:

- Evaluation of the internal temperature

- Examination of the effect of building orientation on the indoor ambient temperature;

- Analysis of total solar radiation absorbed according to several orientations during summer period;

- Analysis of total solar radiation absorbed according to various orientations during winter period.

In order to obtain the optimal orientation, an evaluation of the possible orientations was carried out in which the orientation axis was rotated at an angle of $15^{\circ}$ from the north. To this end, the heat transfer between the indoor and outdoor building spaces must be ensured by the same quantity of cooling and heating energy. Alternatively, the necessary quantity of cooling and heating energy can be provided in different directions to maintain a stable temperature in the living room and comfort zones.

\subsubsection{Impact of the Building orientation}

Figures 13 and 14 demonstrate the effect of the exterior wall's orientation on interior temperatures during the summer and winter seasons. The change of orientation, which occurs more distinctly in the case of the semicentral southeast, north-east and south-west directions, must be taken into account in particular. It should also be noted that the northern orientation resulted in a temperature decrease of $0.5^{\circ} \mathrm{C}$ with respect to the southern orientation, although the difference between the counter-orientation and the correct temperature orientation corresponds to $2^{\circ} \mathrm{C}$, as shown in "Fig 13 ". On the other hand, the North and South orientations in summer are generally the most favorable, compared to the West and East orientations, which should be avoided, given the temperature increases observed over a 24-hour period.

Figure 14 reveals that in winter, the influence of orientation can still be perceived, particularly for the semi-cardinal orientation. As far as temperature records are concerned, the south-eastern direction is considered the best. This can be attributed to the high amount of energy accumulated in the walls and windows. Between 12:00 and 18:00, compared to the other two orientations (northeast and southeast), the average temperature in the southwest direction increased by about $2^{\circ} \mathrm{C}$, resulting in a minor increase of about $1.05^{\circ} \mathrm{C}$ northeast and $1.09^{\circ} \mathrm{C}$ in the southeast orientation. Indeed, the strong temperature increase on the southwestern facade is due to the fact that the influence of solar radiation in the afternoon hits the facade at an angle close to the vertical direction (heat transfer). Indeed, the internal temperature of each zone studied depends strongly on the influence of the direction. 
(Syakubu et al. 1992) and (Borong et al. 2004) confirmed these results.

In the period from 8:00 a.m. to 12:00 p.m., the average indoor temperature of the building facing northeast is about $2{ }^{\circ} \mathrm{C}$ which is lower than the average indoor temperature of buildings facing southeast; this is due to the influence of radiation on both directions and the northeast wind. Nevertheless, compared to the southeast direction, the radiation time is reduced by about $50 \%$. As for the average interior temperature of the south-west façade in the morning, it is about $3{ }^{\circ} \mathrm{C}$ lower than the average temperature in the other two directions, which can be explained by the total absence of solar radiation along the façade and the effect of natural ventilation. These results are in accordance with the results of (Givoni, 1978) and (Boussalh et al. 2009) who have validated that indoor temperature depends largely on the effectiveness of natural ventilation and solar protection. As for the SouthEast and South-West orientations, they are less favorable than the orientation South, with a temperature decrease compared of than those in the South which is automatically due to the sun's course, this permit them to be they are less exposed. However, during this period, North, North East and North West orientations are being avoided since the lowest indoor temperatures affect the level of indoor comfort.

The results of the simulation, graphically illustrated, reflect the orientation effect and reflect the substantial change in the conditions of comfort received. The present study therefore demonstrates the role of the external wall enclosure in providing the thermal comfort required. The control of architectural design parameters as a function of solar radiation, wind and shade play a role in the indoor thermal performance and permit to create comfortable indoor climate (El Azhary et al. 2019). Builders have used temperature variations to achieve good air distribution in buildings. Builders used these combinations to achieve a controlled temperature inside the house, mostly due to the fact that a courtyard or central hall was constructed around the dwellings. When the solar radiation faces the courtyard, the weight of heat flow reduces and increases above the open courtyard.

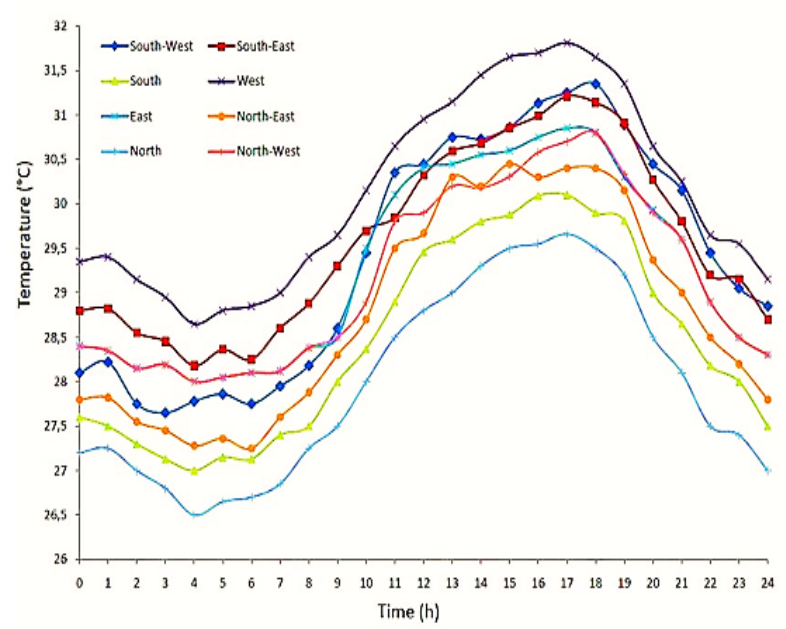

Fig. 14 variation of indoor temperatures according to different orientations during the summer season

\subsubsection{The optimal orientation}

Graph 15 presents the quantity of solar radiation absorbed by the external wall according to different orientations, ranging from $165^{\circ}$ East to $195^{\circ}$ West, which benefits from the solar radiation in summer following the North. In contrast to the East and West orientations, both of which provide the highest solar heat gain. Indeed, "Fig 15 " shows the solar irradiation for moderately bright days absorbed by a wall for different orientations, in which orientations from $150^{\circ}$ East to $195^{\circ}$ West profit from the greatest energy gains.

Consequently, the most efficient orientation is the one which adapts best to the prevailing climate, thus limiting solar gain so as to minimize demand for heating and air conditioning. The comparison results corresponding to the different orientations of the facades demonstrate that the required comfort temperatures are partially reached, while considering the limits of the comfort zone, specifically those of Rissani City, where the average relative humidity ranges from $19 \%$ to $65 \%$ and the relative indoor temperature ranges from $28^{\circ} \mathrm{C}$ to $34^{\circ} \mathrm{C}$. However, many criteria are involved, namely: façade orientation, solar gain control, exterior façade and the integration of bioclimatic design features.

This combination enables the energy requirements of air conditioning and heating to be minimized, along with maintaining a good delivery of heat in spaces during all seasons.

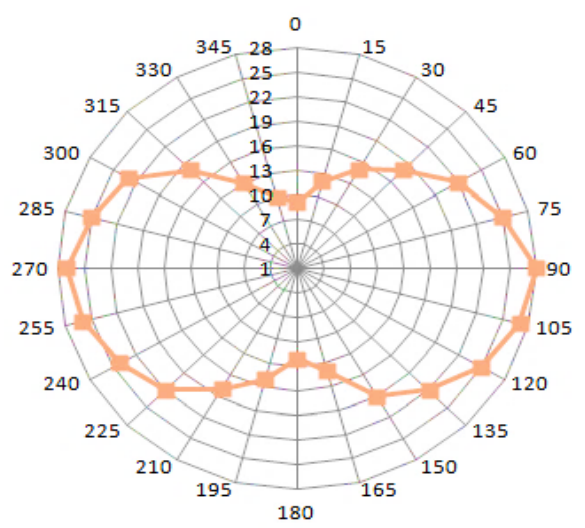

Fig. 15 Total absorbed radiation according to different orientations during summer period $\left(\mathrm{kWh} / \mathrm{m}^{2}\right)$

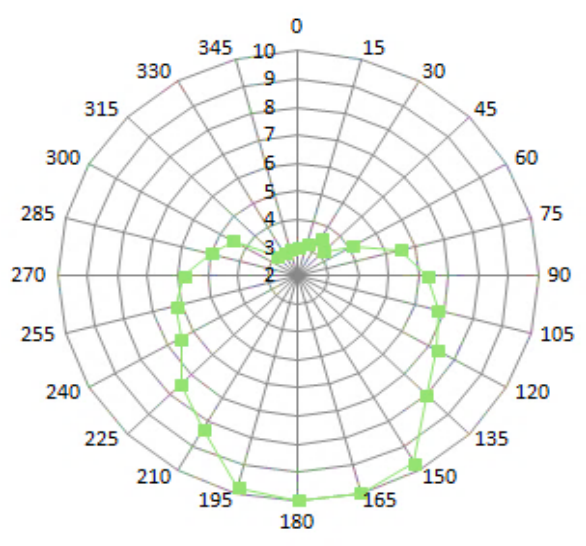

Fig. 16 Total absorbed radiation according to different orientations during winter period $\left(\mathrm{kWh} / \mathrm{m}^{2}\right)$ 


\section{Discussion}

Recently, and progressively, policymakers and professionals in the construction industry in Morocco are recognizing the pressing need for a more sustainable approach to building architecture and construction. It is claimed that the best way for the country to minimize the growing rate of emissions and to reduce electricity is by the implementation of strict environmental and sustainability standards in construction practice. Environmentally speaking, Morocco, which is the same as other developing and emerging countries, is unable to cope with the rising demand for oil. According to the Situation Assessment and Task Force reports, both efforts are now aimed at contributing to addressing this issue by a resource-efficient housing system and a reduction in electricity usage. Moreover, without endorsing energy efficiency gains in the construction industry, Morocco will not achieve the $\mathrm{CO}_{2}$ emission mitigation goals by the year 2030, which should take the vernacular principles into account as a sustainable and efficiency guide and reference.

Today, the implementation of the Moroccan General Construction Regulation setting the rules of energy performance is proving to be an economic and social priority in view of the growth in energy demand and the considerable bill. The energy/environment issue should lead to a transition towards an optimal use of energy in the operation of buildings by using urban climate design methods, bioclimatic architecture principles, and energysaving practices.

Improving the comfort of urban spaces that also improves the comfort inside the housing, the decrease in energy consumption, including the optimization of energy needs in terms of heating during winter and cooling during summer, and reducing carbon emission are among the objectives of urban climate design in urban development. Examples of intelligent structures which are well suited to the local environment are vernacular structures. Vernacular buildings were able to achieve significant energy savings by self-regulating the better understands of vernacular know-how, and the continuous series of trails and mistakes. To achieve energy efficient, convenient and natural spaces. The key approach is to create energy-efficient, comfortable and natural spaces by low-cost passive process and, with the use of existing and local resources.

One of the many variables affecting vernacular architectural forms, such as socio-cultural structure, economy, materials, and technology, is climate. The climate in the regions of Western Morocco plays a significant role in the creation and variety of the region's vernacular houses. Environmental factors in the area, which has a warm-humid climate, such as rain, wind, humidity and sunshine, The Moroccan vernacular buildings are likely to experience hot arid climate, where temperatures are normally extreme, that can increase thermal discomfort. Such buildings primarily require cold protection which can increase passive solar heating. A dense and compact settlement structure and construction plan is suggested, in addition to the high thermal mass of the walls, floor and roof. It has been further clarified that only small openings are acceptable.

In the arid environments of Morocco, the vernacular devices proposed as solutions take into consideration the local and surrounding urban morphology, climatic scenarios, climate and the aesthetic nature of each region during offer an attractive and comfortable environment. Three main restrictions of this type of atmosphere are referred to certain environmental planning configurations: direct or diffuse solar radiation and regulation of air quality. The structures are positioned side by side, a design that causes the outer openings to be limited and aims at a socially awkward typology. This building configuration is based on the combination of a strategy of compactness and the passive vernacular devices in its design, which reduces gains and heat losses with the objective of reducing energy consumption (Abdelsalam \& Rihan, 2013). In this climate, the studied examples of vernacular houses display few features that would increase passive solar heating. The protection from the cold by thick heavy walls, very tiny windows and a very dense settlement layout is given priority. The construction architecture should be optimized to better use natural resources such as solar radiation and wind so as to face the climate change and be more adapted to modern lifestyles (Zune et al.2020).

Utilizing passive, low-energy techniques to provide human warmth, the inclination to adapt to environmental conditions; approaches that are central to the layout, orientation and materiality of the buildings were not a major consideration in the construction strategies for newly constructed structures, either residential or for tourist purposes. It therefore illustrates the value of maintaining a correct interpretation of the local constructed heritage in order to obtain thermal comfort, which was totally neglected in most buildings there. Further research is needed to translate these traditional strategies into the modern context and come up with appropriate building techniques and solar energy integration for the fast developing construction sector of the country.

Climatic conditions represent deciding factor in earthen vernacular buildings. Controlling envelope and architectural conception factors related to solar radiation, wind and shadows conduct actively in ensuring comfortable and efficient thermal performance within the interior space thick walls build with earth can prevent extreme outdoor temperature conditions and contribute to natural thermal regulation and allow energy saving. In this research paper, the evolution of temperature variations, the choice of building materials, insulation conditions and thermal comfort located in hot and arid regions has been evaluated.

To this end, an experimental and numerical study was carried out to study the thermal behavior of a traditional building. Several samples were taken in situ and characterized using standardized experimental methods. The measured thermophysical properties were then used as input data in dynamic thermal simulations on the same building by choosing the most unfavorable period of the year. The results demonstrated the link between the amounts of energy absorbed by the wall at the interior temperature, which is closely dependent on orientation. According to the analysis carried out, the favorable orientation for the control of thermal comfort is south for this type of climate. On the other hand, north orientation should be avoided. As for the East and West orientations, the deficit is $45 \%$.

Due to the fact that it is constructed and designed with local materials using the least amount of resource waste, the proposed building configuration can be seen as the one 
of the sustainability cores of Morocco. Many solutions can also be found to optimize the use of resources and to achieve human thermal comfort by assessing vernacular architecture techniques without appealing to cooling or heating systems. As the building sector is energy intensive and consumes almost $25 \%$ of the energy needed for heating, air conditioning and ventilation of the envelopes to ensure good thermal comfort. Mainly, this energy comes essentially from fossil fuels (oil, coal, natural gas). Vernacular architecture integrates a multitude of restrictions from contexts where it belongs, one of the major attributes of the use of regional materials and techniques. Vernacular materials have low environmental consequences as compared to industrially manufactured materials, becoming an option for sustainable buildings.

Considering that conventional materials are closely related to environmental factors and have slightly less environmental and energy effects than modern building materials, their use demonstrates the potential to reduce impacts on the construction solution's life cycle and to have carbon-negative buildings. Architecture should also pursue dignity in order to attain sustainability. Thus, architecture in Morocco should pursue convergence between tradition and contemporaneity in order to achieve sustainability, using the best of all technology and materials and solar energy integration (Guno et al.2020), (Vares et al.2020). Promoting the use of local and zero emissions materials will have a positive effect on local social and economic growth. It is necessary to provide a framework that offers a comprehensive repository for information on all forms of local and recycled construction materials though as an exchange of expertise with most construction professionals. Thus, government needs to undertake strategies as part of a larger process to improve the design-decision-making process: by offering new insights to other factors or variables integral to the reliable material selection process, and challenge researchers and practitioners to give preference to locally produced and recycled products and carbon negative materials in order to provide more sustainable design strategies for the fast-growing building sector that consider the local climatic conditions, while aiming at the reduction of energy-intensive and expensive artificial means to provide comfort (Bayoumi 2018).

\section{Conclusion}

Authors in this work tried to identify the thermal performances of envelopes by minimizing the energy necessary for the heating, air conditioning and ventilation systems thanks to the good orientation of the envelopes and the right choice of building materials with en experimental identification of the thermophysical performances, in particular low thermal conductivity and high thermal capacity, these parameters are intended to feed the new material database BINAYAT that the Moroccan ministry of Energy has recently developed in order to improve the thermal performances of residential buildings.

This research is significant towards the use of vernacular materials and architectural elements in new buildings worldwide to enhance thermal comfort. This paper demonstrates that vernacular climate-responsive architecture can be planned and constructed, delivering thermo-efficient and sustainable conventional new buildings. There is only a very small-scale building for current applications, and further research is still needed. However, for small to medium-size residential buildings, such implementations are a good reference. Otherwise more research studies treating the ventilation aspect and passive cooling is needed to complete the hall aspects of the Ksourian vernacular buildings to be taking into consideration for future buildings implementation.

\section{Nomenclature}

$\begin{array}{lll}\text { Notation } & \text { Designation } & \text { Unit } \\ \mathrm{S} & \text { Surface } & \mathrm{m}^{2} \\ \Delta \mathrm{T} & \text { Temperature difference } & \mathrm{K} \\ \mathrm{e} & \text { Thickness } & \mathrm{m} \\ \mathrm{U} & \text { Voltage } & \mathrm{V} \\ \mathrm{R}_{\mathrm{e}} & \text { Electrical resistance } & \Omega \\ \mathrm{T} & \text { Temperature } & \mathrm{K} \\ \mathrm{a} & \text { Thermal diffusivity } & \mathrm{m}^{2} / \mathrm{s} \\ \mathrm{h} & \text { Global heat exchange coefficient } & \mathrm{W} / \mathrm{m}^{2} \cdot \mathrm{K} \\ \mathrm{bi} & \text { Biot number } & - \\ \mathrm{c}_{\mathrm{p}} & \text { Thermal heat capacity } & \mathrm{J} / \mathrm{kg}^{\mathrm{K}} \mathrm{K} \\ \lambda & \text { Thermal conductivity } & \mathrm{W} / \mathrm{m} \cdot \mathrm{K} \\ \rho & \text { Apparent density } & \mathrm{kg} / \mathrm{m}^{3} \\ \rho \mathrm{c} & \text { heat volume capacity } & \mathrm{kJ} / \mathrm{m}^{3} \cdot \mathrm{K} \\ \phi & \text { Heat flux } & \mathrm{W} \\ \varphi & \text { Heat flux density } & \mathrm{W} / \mathrm{m}^{2} \\ \mathrm{~s} & \text { Sample } & - \\ \mathrm{p} & \text { Polyethylene } & -\end{array}$

\section{References}

Abdelsalam, T., \& Rihan, G. M. (2013). The impact of sustainability trends on housing design identity of Arab cities. HBRC Journal, 9(2), 159-172.

Degiovanni, A., Laurent, M., \& Prost, R. (1979). Mesure automatique de la diffusivité thermique. Revue de Physique Appliquée, 14(11), 927-932.

Alexandroff, G. \& Alexandroff, J-M., Architectures and Climates Sun and Natural Energies in the habitat, Paris, France: Berger-Levrault, 1982.

Al-Mukhtar, M., Khattab, S., \& Alcover, J. F. (2012). Microstructure and geotechnical properties of lime-treated expansive clayey soil. Engineering geology, 139, 17-27.

Architecture and Energy Efficiency: Ten Cases of Good Practice in Morocco, National School of Architecture, Edition November 2016

ASHRAE, 2010. ANSI/ASHRAE Standard 55 - Thermal Environmental Conditions for Human Occupancy, Atlanta.

Standard, A. S. T. M. (2013). E1461-13. Standard Test Method for Thermal Diffusivity by the Flash Method, ASTM International, West Conshohocken, PA.

Azhary, K. El, M. Lamrani, S. Raefat, N. Laaroussi, M. Garoum, M. Mansour, and M. Khalfaoui. 2017. "The Improving Energy Efficiency Using Unfired Clay Envelope of Housing Construction in the South Morocco." Journal of Materials and Environmental Science 8 (10).

Azhary, K.E., Y. Chihab, M. Mansour, N. Laaroussi, and M. Garoum. 2017. "Energy Efficiency and Thermal Properties of the Composite Material Clay-Straw.” Energy Procedia 141. https://doi.org/10.1016/j.egypro.2017.11.030.

Azhary, Karima El, Saad Raefat, Najma Laaroussi, and Mohammed Garoum. 2018. "Energy Performance and Thermal Proprieties of Three Types of Unfired Clay Bricks." In Energy Procedia, 147:495-502. ElsevierLtd. https://doi.org/10.1016/j.egypro.2018.07.059.

Azhary, K. E., Ouakarrouch, M., Laaroussi, N., Garoum, M., \& Mansour, M. (2020). Impact of Traditional Architecture on the Thermal Performances of Building in South Morocco. In Green Buildings and Renewable Energy (pp. 339-347). Springer, Cham.

Barros, R., Rodrigues, H., Varum, H., Costa, A., \& Correia, M. (2017). Seismic Analysis of a Portuguese Vernacular 
Building. Journal of Architectural Engineering, 24(1), 05017010." n.d.

Bayoumi, O. A. M. (2018). Nubian Vernacular architecture \& contemporary Aswan buildings' enhancement. Alexandria Engineering Journal, 57(2), 875-883

Borong, L., Gang, T., Peng, W., Ling, S., Yingxin, Z., \& Guangkui, Z. (2004). Study on the thermal performance of the Chinese traditional vernacular dwellings in Summer. Energy and Buildings, 36(1), 73-79.

Delaigue, Marie-Christine; El Hraiki, Rahma (2015), Mujeres y Casas En El Medio Rural Del Norte de Marruecos. Una Aproximación Etnografica. In Diez Jorge, M. Elena;Navarro Palazón, Julio (Ed.), ”El Espacio Doméstico En La Península Ibérica Medieval. Socie.

Dietel, J., Warr, L. N., Bertmer, M., Steudel, A., Grathoff, G. H., \& Emmerich, K. (2017). The importance of specific surface area in the geopolymerization of heated illitic clay. Applied Clay Science, 139, 99-107.

Djeradi M. A. (2012), Ksourian Architecture (Algeria) Between Signs and Significance Vernacular Architecture, Tome 3637

E.N. ISO, 8302 (1991) Thermal Insulation-Determination of Steady-State Thermal Resistance and Related PropertiesGuarded Hot Plate Apparatus, Int. Organ. Stand. Geneva, Switz. (1991)

Fernandes, J. E. P., Debaieh, M., Mateus, R., Silva, S. M., Bragança, L., \& Gervásio, H. M. S. (2018). Thermal Performance and Comfort of Vernacular Earthen Buildings in Egypt and Portugal.

Givoni, B. Man, Architecture and the Climate, Paris, France: Moniteur Editions 1978.

Global Weather Database, Meteonorm Software, Version 7, 1991 2010, CSTB Edition.

Guno, C. S., Agaton, C. B., Villanueva, R. O., \& Villanueva, R. O. Optimal Investment Strategy for Solar PV Integration in Residential Buildings: A Case Study in The Philippines. International Journal of Renewable Energy Development, 10(1), 79-89.

Hall, M., \& Allinson, D. (2009). Analysis of the hygrothermal functional properties of stabilised rammed earth materials. Building and Environment, 44(9), 1935-1942.

Herrero, S., Mayor, P., Hernández-Olivares, F. (2013). Influence of proportion and particle size gradation of rubber from end-of-life tires on mechanical, thermal and acoustic properties of plaster-rubber mortars. Materials and Design, 47, 633-642,

Hyde R, 2008. Bioclimatic Housing: Innovative Designs for Warm Climates. London: Earthscan. Imesch T, Thomann HU, 1991. Timimoun, Habitat Du Sahara. Paris: Institut of Arabic world

Nelder, J. A., \& Mead, R. (1965). A simplex method for function minimization. The computer journal, 7(4), 308-313

Laaroussi, N., El Azhary, K., Garoum, M., Raefat, S., \& Feiz, A. (2016, July). Semi-empirical models for the estimation of global solar irradiance measurements in Morocco. In 2016 3rd International Conference on Renewable Energies for Developing Countries (REDEC) (pp. 1-6). IEEE.

Liébard A., Ménard J.-P. et Piro P. (2007), Le Grand Livre De L'Habitat Solaire: 110 Achievements In France Sustainable Development Within Everybody's Reach, Observ'ER, LE MONITEUR, Gaz de France, Paris,

Mecca S., (2006), Architecture in the Drâa Valley, Morocco, First International Congress on Oasis and Sustainable Tourism, University of Alicante, Elche.

Mecca S., Tonietti U., Rovero L, (2007), Knowledge in Construction and Cultural Diversity of Earthen Architecture in Tamnougalt (Zagora, Maroc), RIPAM2, University Cadi-Ayyad, Marrakech Morocco.

Mecca S. and Biondi B. Eds, (2005), Architectural Heritage and
Sustainable Development of Small and Medium Cities in South Mediterranean Regions, Proceedings of First International Research Seminar, Forum UNESCO University and Heritage, Florence, 27th-2.

Mohsen H.Aboul Naga, Yasser H.El Sheshtawy, Environmental Sustainability Assessment of Buildings in Hot Climates: The Case of the UAE, Renewable Energy, Volume 24, Issues 3-4, November 2001, Pages 553-563.

"NF P 75 101: 'Norme Française: Isolants Thermiques Destinés au Bâtiment', October 1983.

Ouakarrouch, M., El Azhary, K., Mansour, M., Laaroussi, N., \& Garoum, M. (2020). Thermal study of clay bricks reinforced by sisal-fibers used in construction in South of Morocco. Energy Reports, 6, 81-88.

Ouakarrouch, M., Garoum, M., \& Laaroussi, N. (2019, November). Experimental Study of Thermophysical Proprieties of Wooden Materials used in Building Construction. In 2019 7th International Renewable and Sustainable Energy Conference (IRSEC) (pp. 1-5). IEEE,.

Ouakarrouch, M., El Azhary, K., Laaroussi, N., Garoum, M., \& Kifani-Sahban, F. (2020). Thermal performances and environmental analysis of a new composite building material based on gypsum plaster and chicken feathers waste. Thermal Science and Engineering Progress, 19, 100642.

Ouakarrouch, M., Kifani-Sahban, F., Laaroussi, N., Garoum, M., \& Layakhaf, S. M. (2018, December). Thermal Insulation and Operation by Photovoltaic Solar Energy of a Bioreactor. In 2018 6th International Renewable and Sustainable Energy Conference (IRSEC) (pp. 1-5). IEEE.

Raefat, S., Garoum, M., Laaroussi, N., Thiam, M., \& Amarray, K. (2017, July). Thermal diffusivity and adiabatic limit temperature characterization of consolidate granular expanded perlite using the flash method. In IOP Conference Series: Materials Science and Engineering (Vol. 222, No. 1, p. 012004). IOP Publishing.

Ravéreau, A., From Local to l'universal, Paris, France: Linteau Edition 2007.

RPCT 2011: Paraseismic Regulation of Earthen Buildings (MAROC).

Sayigh, A. (2013). Sustainability, energy and architecture: Case studies in realizing green buildings. Academic Press.

Schatz, J. F., \& Simmons, G. (1972). Thermal conductivity of earth materials at high temperatures. Journal of Geophysical Research, 77(35), 6966-6983.

Terrasse H., Berber Kasbahs of the Atlas and Oasis, Editions of Horizons France, Paris, 1938

Thermal Regulation of Construction in Morocco, RTCM, The Moroccan Agency for Energy Efficiency - AMEE, 2012, Moroccan Agency for Energy Efficiency (AMEE) $<$ www.Amee.Ma.

Vares, S., Savolainen, P., Häkkinen, T., Shemeikka, J., Huttunen, M., \& Zubillaga, L. (2020, November). Concepts and type building for carbon neutral construction in arctic Finland based on tradition. In IOP Conference Series: Earth and Environmental Science (Vol. 588, No. 2, p. 022032). IOP Publishing.

W.J. Parker, R.J. Jenkins, C.P. Butler, G.L. Abbott, Flash Method of Determining Thermal Diffusivity, Heat Capacity, and Thermal Conductivity, J. Appl. Phys. 32 (1961) 1679-1684.

Jannot, Y., Degiovanni, A., Félix, V., \& Bal, H. (2011). Measurement of the thermal conductivity of thin insulating anisotropic material with a stationary hot strip method. Measurement Science and Technology, 22(3), 035705 .

Zune, M., Pantua, C. A. J., Rodrigues, L., \& Gillott, M. (2020). A review of traditional multistage roofs design and performance in vernacular buildings in Myanmar. Sustainable Cities and Society, 60, 102240. 